Arq. Bras. Med. Vet. Zootec., v.70, n3, p.913-920, 2018

\title{
Coturnicultura como alternativa para aumento de renda do pequeno produtor
}

[Quail production as an alternative to improve income to small farmers]

\author{
A.F. Silva ${ }^{1}$, S. Sgavioli ${ }^{2 *}$, C.H.F. Domingues ${ }^{1}$, R.G. Garcia ${ }^{1}$ \\ ${ }^{1}$ Universidade Federal da Grande Dourados - Dourados, MS \\ ${ }^{2}$ Universidade Brasil - Descalvado, SP
}

\begin{abstract}
RESUMO
A coturnicultura tem apresentado desenvolvimento significativo nos últimos anos devido às tecnologias empregadas na cadeia produtiva, gerando resultados satisfatórios aos produtores, com baixo custo de investimento. $\mathrm{O}$ estudo teve como objetivo avaliar a viabilidade econômico-financeira da coturnicultura para o pequeno produtor rural ou agricultor familiar. Foram utilizados dois grupos com 1.500 aves cada, A1 (aquisição de lote misto com um dia de idade) e A2 (aquisição de fêmeas com 35 dias de idade), e empregados a taxa interna de retorno, o payback simples e o descontado, bem como o valor presente líquido para a análise econômico-financeira. A coturnicultura representa uma alternativa em potencial para agregação de renda ao pequeno produtor/agricultor familiar, pois o retorno do investimento ocorre no segundo ano. Para o início da produção coturnícula, a aquisição de fêmeas aos 35 dias de idade é mais rentável, quando comparada à aquisição de lote misto com um dia de idade. Dessa forma, a alternativa estratégica de comercialização para o início da atividade é o ovo in natura, que possibilita o retorno do investimento em curto prazo.
\end{abstract}

Palavras-chave: agronegócio, análise econômica, codornas, economia

\begin{abstract}
Quail production showed significant development in recent years due to technologies used in the production chain, generating satisfactory results for farmers with low cost of investment. The purpose of this study was to evaluate the economic feasibility of quail production implementation for small farmers. A total of 3,000 birds were used and divided in two groups (A1 and A2). The internal rate return was measured, as well as simple payback. The present liquid value for economic and financial analysis was discounted. Quail production is a potential alternative for income increase of small farmers, since the return on investment occurs in the second year. To start quail production, the acquisition of female quails at 35 days of age is more profitable compared to a one day old mixed batch. Thus, the alternative marketing strategy for the beginning of activity is the egg, due to the return on short-term investment.
\end{abstract}

Keywords: agribusiness, economic analysis, economy, quail

\section{INTRODUÇ̃̃̃}

A coturnicultura é um segmento da avicultura brasileira que cria, melhora e fomenta a produção de codornas. $\mathrm{O}$ aumento do interesse pela coturnicultura pode ser percebido pelo crescimento de estudos acadêmicos sobre questões de melhoramento genético, nutrição, manejo, equipamentos para a produção das aves e também para a tecnificação na produção de ovos (Bertechini, 2010).

Os maiores centros coturnicultores brasileiros estão nos estados de Minas Gerais e São Paulo, porém há presença da criação de codornas em outras regiões do Brasil. No Centro-Oeste, ainda há poucos registros da coturnicultura (IBGE, 2012).

Recebido em 7 de junho de 2017

Aceito em 29 de agosto de 2017

*Autor para correspondência (corresponding author)

E-mail: sarahsgavioli@yahoo.com.br 
Esse segmento é uma opção para a exploração avícola, pois é uma cultura com manejo simplificado (Bertechini, 2010). Segundo Matos (2007), as codornas possuem as seguintes qualidades: rápido crescimento; precocidade sexual; postura e rusticidade elevadas e baixo consumo de alimento. Para a implantação das granjas, demanda-se pequeno espaço físico (em comparação a outras criações) (Kato, 2007). Portanto, economicamente a coturnicultura exige um baixo investimento, com rápido retorno econômico, se comparada à avicultura de frangos de corte, que demanda um alto investimento (Pastore et al., 2012). Desse modo, a agricultura familiar ou pequeno produtor pode utilizá-la como uma alternativa para agregar renda, melhorar sua participação no mercado e aumentar seus lucros sem alterar sua configuração produtiva.

A agricultura familiar ou pequeno produtor exerce uma função vital para a promoção do desenvolvimento regional, portanto deve-se assegurar a esse segmento o acesso a políticas de crédito, entre outros benefícios (Sangalli e Schlindwuin, 2013). Para Santos (2012), o papel do agricultor familiar vai além de produzir alimentos, pois gera renda, proporciona desenvolvimento local e fixa o homem no campo, contribuindo para a reprodução histórica dos valores sociais de cada grupo.

No modelo de agricultura familiar, a área disponível é destinada à construção das casas e a pequenos cultivos de subsistência, como frutas, mandioca, hortaliças e à criação de animais, como vaca leiteira, para o sustento familiar (Reforma..., 2015). Mediante essa configuração, a coturnicultura pode ser uma alternativa para agregar renda ao produtor.

O pequeno produtor rural/agricultor familiar pode ser atendido por linhas de créditos oferecidas pelo Governo Federal, por meio do Programa Nacional de Fortalecimento da Agricultura Familiar - Pronaf. Esse programa representa uma ação relevante na distribuição de ativos (crédito) (Abramoway e Piketty, 2005). No biênio 2015/2016, o Plano Safra ofereceu R\$ 28,9 bilhões para investimento e custeio destinado ao pequeno agricultor/agricultor familiar, com taxas de juros entre 2 a 5,5\% a.a (ao ano), de acordo com a linha de crédito e a destinação do recurso (Brasil, 2006). Entre as alternativas contidas no Pronaf, o pequeno agricultor pode optar pela linha de crédito "Pronaf Custeio", na faixa II, com limites creditícios acima de $\mathrm{R} \$ 10$ mil até o teto de $\mathrm{R} \$$ 30 mil, com juros de $4,5 \%$ a.a.

Diante do exposto, o presente estudo teve por objetivo avaliar a viabilidade econômicofinanceira da implementação da coturnicultura para o pequeno produtor, em Ponta Porã, Mato Grosso do Sul, Brasil. Também verificou-se a preferência das formas de comercialização dos ovos de codorna, o que demonstra os custos da produção coturnícula e a viabilidade de investimento como uma alternativa para $\mathrm{o}$ pequeno produtor no estado de MS.

\section{MATERIAL E MÉTODOS}

Foram considerados dois modelos de criação: o primeiro, com aves de um dia de idade, em lote misto (machos e fêmeas), denominado ave 1 (A1), no qual o produtor realiza toda a fase de cria até 30 a 35 dias de idade, e, então, os machos são separados para a fase de terminação (produção de carne) e as fêmeas para a produção de ovos; o outro modelo, com um lote de aves na fase de recria com 30 a 35 dias de idade, denominado ave 2 (A2), no qual foi realizado o estudo de viabilidade para a produção de ovos. A quantidade de codornas para o início da atividade foi de 1.500 aves/modelo de criação, totalizando 3.000 aves.

Para a realização dos cálculos, utilizou-se um ciclo de postura de 12 meses, a partir dos 35 dias de idade das aves. A densidade, utilizada por $\mathrm{m}^{2}$, seguiu o sugerido por Murakami e Ariki (1998), sendo de 50 aves $/ \mathrm{m}^{2}$ para as aves criadas em piso e de 100 aves $/ \mathrm{m}^{2}$ para as aves alojadas nas gaiolas.

A análise da escolha do sistema para o grupo A1 foi realizada considerando-se fase única de criação, ou seja, as codornas não são transferidas antes de atingirem o ciclo de 30 a 35 dias.

Para a fase de postura, o manejo deve evitar barulho, movimentação desnecessária, falta de água e/ou ração para não estressar as aves. A oferta de água deve ser constante e à vontade, e o fornecimento de ração deve ocorrer de duas a 
três vezes ao dia, com cuidado, para se evitar o desperdício (Murakami e Ariki, 1998).

Em relação à construção/adaptação do galpão, foram realizadas visitas em lojas de materiais de construção e de ferragens da região de Ponta Porã, Mato Grosso do Sul, Brasil, para cotar o preço dos insumos necessários.

O manejo foi simples e breve e podendo ser utilizada a mão de obra da própria família, não sendo contabilizado esse custo nos cálculos durante a criação. Além deste, custos com energia elétrica e água não foram contabilizados por serem baixos e difíceis de serem mensurados, em uma criação em pequena escala.

Para a avaliação dos custos produtivos, foram adotados os conceitos propostos por Matsunaga et al. (1976), em que o custo operacional efetivo (COE) e o custo operacional total (COT) são avaliados. O COE englobou o uso de mão de obra, máquinas, equipamentos, instalações, veículos e insumos. Já o COT foi obtido pelo resultado do $\mathrm{COE}$ somado às despesas de depreciação de máquina e equipamentos. Também foi analisada a taxa interna de retorno (TIR), representada pela equação 1 :

$C F_{0}=\frac{F c 1}{(1+i)}+\frac{F c 2}{(1+i)^{2}}+\frac{F c 3}{(1+i)^{3}}+\cdots+\frac{F c n}{(1+i)^{n}}$

(Eq. 1)

em que:

$\mathrm{CF}_{0}$ : fluxo de caixa inicial;

Fcn: fluxo de caixa por período.

A avaliação do valor presente líquido (VPL) analisa a viabilidade econômica, considerando-se o valor do investimento futuro no presente, ou

seja, permite ao gestor analisar o investimento em valores atuais (Sabbag e Nicodemos, 2011), representado pela equação 2 :

$V P L=\frac{F c l}{(1+i)}+\frac{F c 2}{(1+i)^{2}}+\frac{F c 3}{(1+i)^{3}}+\cdots+\frac{F c n}{(1+i)^{n}}-C F_{0}$

(Eq. 2)

em que:

Fcn: fluxo de caixa por determinado período;

CF0: fluxo de caixa inicial para o começo do projeto;

i: taxa de juros;

n: período.

Nesta pesquisa, foram utilizados os juros máximos aplicados pelo Pronaf, de 4,5\% a.a., que foram convertidos para ao mês (a.m.), obtendo-se $0,37 \%$, pois os resultados serão apresentados por mês. Utilizou-se a metodologia payback (Avaci et al., 2013), com a finalidade de

$\operatorname{FCC}(t)=-1+\sum_{j=1}^{t} \frac{\left(R_{j}-C_{j}\right)}{(1+i)^{j}}$

(Eq. 3)

em que:

FCC: representa o valor do investimento descontado;

I : representa o investimento inicial;

Rj: receita do período;

$\mathrm{Cj}$ : custo do período;

i: taxa de juros utilizada;

j: período. avaliar o período para o retorno do investimento. O payback descontado trabalha com o fluxo de caixa, considerando-se a taxa de juros necessária para se obter o financiamento, que, no caso, é de 0,37\% a.m., de acordo com a equação 3: 


\section{RESULTADOS E DISCUSSÃO}

O galpão para a criação das aves foi dimensionado com $5 \mathrm{~m}$ de largura $\mathrm{x} 6 \mathrm{~m}$ de comprimento, portanto com $30 \mathrm{~m}^{2}$, com pé direito de $2,5 \mathrm{~m}$, piso cimentado com cobertura de telha de barro, muretas laterais de $80 \mathrm{~cm}$, complementado com sacos de ráfia e tela metálica (Tabela 1). O dimensionamento do galpão atendeu às condições necessárias para a criação tanto do grupo A1 quanto do grupo A2. Além disso, os dados da Tabela 1 demonstram o investimento necessário para a construção de seis gaiolas com capacidade para alojar 250 aves cada, durante a fase de postura e também para a fase de terminação. Ambos os valores foram utilizados nas criações A1 e A2.

Tabela 1. Investimento necessário para a construção de um galpão de alvenaria com cobertura de telha de barro com capacidade de alojamento de 1.500 codornas na fase de postura e de seis gaiolas artesanais

\begin{tabular}{ccccc}
\hline Item & Unidade $/ \mathrm{m}^{2}$ & Quantidade & Valor unitário* $-\mathrm{R} \$$ & Valor total - R\$ \\
\hline Viga $4 \mathrm{mt}$ & Unidade & 12 & 40,00 & 480,00 \\
Caibro & Unidade & 12 & 7,00 & 84,00 \\
Ripa & Unidade & 24 & 3,50 & 84,00 \\
Telha & Unidade & 672 & 1,55 & $1.041,60$ \\
Prego & Pacote & 2 & 7,70 & 15,40 \\
Tijolo & Unidade & 440 & 0,75 & 330,00 \\
Cimento & Unidade & 24 & 30,00 & 720,00 \\
Ferro & Unidade & 5 & 15,00 & 75,00 \\
Caibro & Unidade & 24 & 7,00 & 168,00 \\
Forro PVC & $\mathrm{m}^{2}$ & 18 & 9,00 & 162,00 \\
Tela & $\mathrm{m}$ & 48 & 5,00 & 240,00 \\
Bebedouro & Unidade & 90 & 2,20 & 198,00 \\
Ripão & Unidade & 12 & 3,50 & 42,00 \\
Comedouro & Unidade & 30 & 9,00 & 270,00 \\
Mão de obra & & & & $1.470,00$ \\
Total & & & & $5.380,00$ \\
\hline
\end{tabular}

* Valores pesquisados em outubro de 2015, em Ponta Porã, MS, em loja especializada de materiais de construção.

A opção por comprar gaiola do tipo industrializada foi desprezada, uma vez que, além do valor de compra, o produtor ainda teria a despesa com a depreciação. Portanto, optou-se pela construção de gaiolas artesanais (Tab. 1).

A Tabela 2 apresenta os custos para a aquisição de 1.500 aves para ambos os grupos experimentais (A1 e A2). Para o grupo A1, durante a fase de crescimento, há a possibilidade de mortalidade em torno de $5 \%$ do plantel inicial, ou seja, do grupo com 1.500 aves sobrevivem, ao final, 1.425 (Murakami e Ariki, 1998). Foi calculada a aquisição de um lote misto, com machos e fêmeas, com um dia de vida (A1), com um custo unitário de $\mathrm{R} \$ 1,58$ e de $\mathrm{R} \$ 1,26$, para fêmeas e machos, respectivamente (Tab. 2). Portanto, o custo médio para aquisição do lote A1 foi de R\$ 1,42/ave. Para o grupo A2, o valor de compra de fêmeas com 35 dias de idade foi de $\mathrm{R} \$ 5,00$ a unidade (Tab. 2).

As aves do grupo A1 (lote de fêmeas e lote de machos) necessitam de 34 dias para completarem a fase de crescimento, de forma que o produtor terá o custo de arraçoamento, expresso por R $\$ / \mathrm{g}$ (valor por grama) com a estimativa de consumo diário de 20g (Murakami e Ariki, 1998).

O valor da ração foi obtido em lojas agropecuárias especializadas em Ponta Porã, em Mato Grosso do Sul, Brasil, ao preço de R\$ 54,00 o saco com 30 quilos (R $\$ 0,0018 / \mathrm{g}$ de ração), portando, considerando-se um consumo de ração de $20 \mathrm{~g} / \mathrm{ave} / \mathrm{dia}$, durante 34 dias, obtevese um valor total de R $\$ 1.836,00$ até os 35 dias idade (Tabela 2). A ração para o início da atividade é comprada e, por isso, torna-se a principal fonte de custo para o produtor, mas, com a solidificação da produção, é possível produzir na propriedade, o que proporcionaria uma redução considerável nos custos e um aumento nos lucros, enquanto as aves do grupo A2 já são adquiridas com o ciclo de cria completo, ou seja, o produtor não gastará com a alimentação. 


\section{Coturnicultura como alternativa...}

Tabela 2. Custo de aquisição das codornas e de ração até 35 dias de idade e a porcentagem de mortalidade para os grupos A1 e A2

\begin{tabular}{|c|c|c|c|c|c|c|}
\hline Codornas* & $\begin{array}{c}\text { Quantidad } \\
\text { e } \\
\text { (a) }\end{array}$ & $\begin{array}{l}\text { Valor } \\
\text { unitário } \\
\text { (b) }\end{array}$ & $\begin{array}{l}\text { Total sem } \\
\text { frete } \\
\text { (a) } x(b)=(c)\end{array}$ & $\begin{array}{l}\text { Custo } \\
\text { do } \\
\text { frete } \\
\text { (d) }\end{array}$ & $\begin{array}{l}\text { Total com } \\
\quad \text { frete } \\
(\mathrm{c})+(\mathrm{d})=(\mathrm{e})\end{array}$ & $\begin{array}{c}\text { Total } \\
\text { unitário } \\
\text { (e)/(a) }\end{array}$ \\
\hline Fêmeas (A1) & 750 & 0,70 & 525,00 & 600,00 & $1.125,00$ & - \\
\hline $\begin{array}{l}\text { Mortalidade } \\
(5 \%)\end{array}$ & 712 & - & - & - & 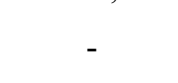 & 1,58 \\
\hline Machos (A1) & 750 & 0,40 & 300,00 & 600,00 & 900,00 & - \\
\hline $\begin{array}{c}\text { Mortalidade } \\
(5 \%)\end{array}$ & 712 & - & - & - & - & 1,26 \\
\hline Aves recria (A2) & 1500 & 4,20 & 6.300 & $1.200,00$ & $7.500,00$ & 5,00 \\
\hline \multicolumn{6}{|c|}{ Custos com ração (A1) até 35 dias de idade (R\$) } & $\begin{array}{c}1.836,00 \\
0,00\end{array}$ \\
\hline
\end{tabular}

* Valores pesquisados em outubro de 2015, em Ponta Porã, MS.

Tendo em vista os valores expressos na Tab. 3, para o grupo A1, houve um custo unitário até 35 dias de idade de $\mathrm{R} \$ 0,06$ e, a partir de 35 dias de idade, de mais $\mathrm{R} \$ 0,06$, totalizando $\mathrm{R} \$ 132,72$, para 1.500 aves, enquanto para o grupo A2, houve_somente o custo de R\$ 0,06 após os 35 dias de idade, totalizando um investimento de $\mathrm{R} \$$ 90,00 para 1.500 aves (Tabela 3). As aves do grupo A1 necessitam do dobro de vacinas, em custo, quando comparadas com as aves do grupo A2. Essa condição eleva o custo e aumenta os riscos para o produtor que optar por trabalhar com aves do grupo A1. As aves do grupo A2 já cumpriram parte do cronograma de vacinação, sendo necessária apenas a complementação.

Tabela 3. Custo para o plano de vacinação detalhado das aves A1 e A2

\begin{tabular}{ccccc}
\hline Ave & Tipo & $1^{\text {a }}$ dose $(\mathrm{a})$ & $2^{\mathrm{a}}$ dose $(\mathrm{b})$ & Total unitário $(\mathrm{R} \$)$ \\
\hline A1 & \multirow{2}{*}{ Newcastle } & 21 dias & 45 dias & 0,04 \\
A2 & & - & 45 dias & 0,02 \\
A1 & Coriza infecciosa & 28 dias & 45 dias & 0,04 \\
A2 & & - & 45 dias & 0,02 \\
A1 & \multirow{2}{*}{ Vermifugação } & 30 dias & 51 dias & 0,04 \\
A2 & & 30 dias & 51 dias & 0,04 \\
\hline
\end{tabular}

A sanidade das aves envolve fatores de boa higiene da estrutura, ventilação adequada, água potável abundante, destinação adequada das codornas mortas, além do cronograma de vacinação (Petrolli et al., 2011). Algumas doenças causam grandes prejuízos econômicos. Há probabilidade maior de incidência dos tipos: doença de Newcastle, coriza infecciosa, além de ser necessária a vermifugação conforme plano de vacinação (Murakami e Ariki, 1998; Matos, 2007).

Aos 35 dias de idade, foram comercializados 712 machos das aves A1, enquanto as 712 aves fêmeas foram destinadas para a postura. Segundo Murakami e Ariki (1998), a idade própria para o abate das aves para a comercialização da carcaça é estimada em torno de 35 dias, na chamada fase de terminação. Considerando-se a taxa estimada de mortalidade em torno de 5\% $(712-5 \%=708)$ do número de aves (Murakami e Ariki, 1998), o produtor terá como custo final, para cada carcaça a ser comercializada, o valor de R\$ 3,05 (total do custo variável divido pelo total de 708 aves). Para garantir um lucro estimado em $30 \%$, cada ave deve ser comercializada por $\mathrm{R} \$ 4,50$. Em média, no período de 35 dias, o produtor conseguirá obter uma receita de $\mathrm{R} \$ 214,60$ com a comercialização das carcaças.

A opção por produção de codornas para corte aponta para uma taxa de lucratividade promissora, pois, pelas suas qualidades nutricionais e pelo sabor diferenciado, tem conquistado o mercado consumidor. Euclydes et al. (2013) salientam que a comercialização de carne de codorna enfrenta a dificuldade para abrir mercados que ainda não consomem $\mathrm{o}$ 
produto. Para que essa alternativa seja viável, serão necessárias estratégias de marketing, ações de publicidade e planejamento estratégico para que a carcaça produzida possa ser comercializada (Nascimento e Reginato, 2009).

De acordo com Murakami e Ariki (1998), o consumo das aves na fase de postura é de $22 \mathrm{~g} /$ dia. Tendo em vista o custo de $\mathrm{R} \$ 0,0018 / \mathrm{g}$, para o grupo A1, com 712 aves, houve um custo total diário de ração de $\mathrm{R} \$ 28,20$, enquanto para o grupo A2, com 1.500 aves, houve um custo total diário de ração de $\mathrm{R} \$ 59,40$.

O ovo in natura comercializado na região custa, em média, R\$ 0,09, conforme pesquisa realizada nos supermercados. Para o produtor escoar sua produção, ele deve ingressar com um valor menor do que o já praticado no mercado (Neves, 2003). A venda dos ovos deve ocorrer em embalagens plásticas contendo 30 unidades cada. Essa quantidade permitirá ao consumidor comparar os preços sem necessidade de realizar cálculos.

Haja vista que a taxa de postura das aves é estimada em 75\% (Murakami e Ariki, 1998) e que as aves começam a botar a partir do $45^{\circ}$ dia, somente a partir dessa data o produtor poderá iniciar sua receita com a venda dos ovos. Para o grupo A1, com 712 aves, houve uma produção de 534 ovos/dia, havendo uma receita de $\mathrm{R} \$$ 48,06 . Considerando-se o custo com a ração de $\mathrm{R} \$ 28,20 /$ dia, obteve-se um lucro líquido de R\$ 19,86 ao dia. Para o grupo A2, com 1.500 aves, houve uma produção de 1.125 ovos/dia, havendo uma receita de $\mathrm{R} \$ 101,25$. Considerando-se o custo com a ração de $\mathrm{R} \$ 59,40 /$ dia, obteve-se um lucro líquido de $\mathrm{R} \$ 41,85$ ao dia.

A produção de ovo teve um custo com ração de aproximadamente $\mathrm{R} \$ 0,053$ a unidade. Para haver retorno, cada ovo deve ser comercializado em torno de $\mathrm{R} \$ 0,09$.

A margem de contribuição por ovo foi de R\$ 0,037 , o que obriga o produtor a ter muita cautela para conseguir assegurar essa margem.
Após o fim do ciclo de postura, quando não é mais possível a produção de ovos, as aves devem ser abatidas e comercializadas. A receita obtida com a venda das carcaças corresponde à receita residual, uma vez que a função principal de produzir ovos já foi concluída (Nascimento e Reginato, 2009). Foi considerada uma taxa de mortalidade de $5 \%$ até o fim do ciclo (Murakami e Ariki, 1998). É possível que, ao final do ciclo de postura, as aves sejam abatidas e comercializadas em embalagens domésticas, atendendo às exigências sanitárias municipais, ao valor de $\mathrm{R} \$ 4,50$ a unidade. Essa receita permite comprar o novo lote de aves para continuar a postura. Para o grupo A1, descontada a mortalidade, havia 708 aves, totalizando R\$ $3.186,00$ com a venda das codornas. Para o grupo A2, descontada a mortalidade, havia 1.425 aves, totalizando $\mathrm{R} \$ 6.412,50$ com a venda das codornas com 47 semanas de idade.

Kato (2007) lembra que a comercialização da carne deve atender às exigências sanitárias do local. Na região de Ponta Porã, não há abatedouros credenciados, o Serviço de Inspeção Sanitária Municipal (SIM) ou o Serviço de Inspeção Sanitária Estadual (SIE). Portanto, o produtor deve escoar a produção para as indústrias de alimentos especializadas.

De acordo com o resumo dos custos e lucros (Tabela4), observou-se que a comercialização de ovos foi a principal alternativa para o início da produção coturnícula, sendo possível, após o segundo ano, aumentar a escala de itens comercializados, com produção de carne, comercialização de esterco e produção de aves para revenda. Porém, essas opções dependem de uma cadeia produtiva estabelecida. Assim, a criação A2 mostrou-se mais rentável que a A1. Além disso, a coturnicultura representa uma alternativa potencial para agregação de renda ao pequeno produtor/agricultor familiar, pois $\mathrm{o}$ retorno do investimento ocorre em curto período de tempo. 
Coturnicultura como alternativa...

Tabela 4. Demonstração do custo total, dos custos variáveis e dos lucros para A1 e A2

\begin{tabular}{|c|c|c|}
\hline \multicolumn{3}{|c|}{ Custo fixo } \\
\hline $\begin{array}{l}\text { Quantidade } \\
\text { (a) }\end{array}$ & $\begin{array}{l}\mathrm{R} \$ \text { unitário } \\
\text { (b) }\end{array}$ & $\begin{array}{l}\text { Total }(\mathrm{R} \$) \\
\text { (a) } \times(\mathrm{b})\end{array}$ \\
\hline Galpão & $4.300,00$ & $4.300,00$ \\
\hline Gaiola artesanal & 180,00 & $1.080,00$ \\
\hline \multicolumn{2}{|c|}{ Total custo fixo (a) } & $5.380,00$ \\
\hline \multicolumn{3}{|c|}{ Custo variável } \\
\hline Item & A1 Custo $(\mathrm{R} \$)$ & A2 Custo $(\mathrm{R} \$)$ \\
\hline Compra aves & $1.172,36$ & $7.500,00$ \\
\hline Ração 1-35 dias & $1.836,00$ & - \\
\hline Ração 35-45 dias & 282,00 & 594,00 \\
\hline Vacinas & 132,72 & 90,00 \\
\hline Total custo variável (b) & $3.423,08$ & $8.184,00$ \\
\hline \multirow[t]{2}{*}{ Custo total geral $(a)+(b)=(c)$} & 8.803 .08 & $13.564,00$ \\
\hline & A1 Lucros $(\mathrm{R} \$)$ & A2 Lucros $(\mathrm{R} \$)$ \\
\hline Venda de carcaças aos 35 dias & 214,60 & - \\
\hline Venda de carcaça com 47 semanas & $3.186,00$ & $6.412,50$ \\
\hline Venda de ovos de 5 - 47 semanas & $5.958,60$ & $12.555,00$ \\
\hline Receitas totais $(\mathrm{d})$ & $9.359,20$ & $18.967,50$ \\
\hline & A1 Lucro líquido $(\mathrm{R} \$)$ & A2 Lucro líquido ( $\mathrm{R} \$)$ \\
\hline Lucro líquido em 47 semanas de criação (d) - (c) & 556,12 & $5.403,50$ \\
\hline
\end{tabular}

Com base no fluxo de caixa descontado (d) (Tabela 4) apresentado, foi possível aplicar o valor presente líquido (VPL). Para o grupo A1, após a aplicação da equação do VPL, obteve-se como resultado o valor de $\mathrm{R} \$ \mathrm{R} \$ 1.140,80$. Esse resultado indica que, se o empreendimento fosse encerrado hoje, esse seria o valor final que o produtor teria disponível em efetivo. Também foi analisada a taxa interna de retorno (TIR) conforme fluxo de caixa descontado (d) representado (Tabela 4). Os cálculos analisaram a possibilidade de o pequeno produtor/agricultor familiar captar recursos por meio do Plano Safra, na classificação Pronaf Custeio, com juros de $4,5 \%$ a.a. que é uma taxa abaixo da praticada no mercado, o que se demonstrou viável, pois os juros mensais do capital investido são de $0,37 \%$ a.m. e a TIR é de $1,94 \%$ a.m.

O payback simples indica que o produtor consegue recuperar o investimento a partir do mês 12. Com a aplicação do payback descontado, considerando-se a taxa anual de $4,5 \%$ a.a. e a taxa equivalente de $0,37 \%$ a.m. fornecida pelo Pronaf Custeio, o produtor demoraria 12 meses para obter o lucro, haja vista que, ao fim dos 12 meses, será incluído um novo lote de aves. O payback simples e o descontado não apresentam diferenças em razão de a taxa de juros para a captação do recurso ser abaixo da praticada no mercado.
Para o grupo A2, o resultado da equação do VPL representa que o valor presente líquido do empreendimento no valor atual corresponde a $\mathrm{R} \$$ 6.669,00. Calculou-se uma TIR de 5,77\%, indicando que o empreendimento é atrativo para o produtor. Ainda para o grupo A2, o payback simples indica que o produtor consegue recuperar o investimento a partir do $11^{\circ}$ mês. Com a aplicação do payback descontado, considerando-se a taxa anual de $4,5 \%$ a.a. e a taxa equivalente de $0,37 \%$ a.m. fornecida pelo Pronaf Custeio, o produtor demoraria 12 meses para obter lucro, haja vista que, ao fim dos 12 meses, será incluído um novo lote de aves. O payback simples e o descontado não apresentam grandes diferenças em razão de a taxa de juros para a captação do recurso ser abaixo da praticada no mercado.

\section{CONCLUSÕES}

A coturnicultura representa uma alternativa potencial para agregação de renda ao pequeno produtor/agricultor familiar, pois o retorno do investimento ocorre no segundo ano de produção. Ao final do primeiro ciclo de postura (12 meses), o coturnicultor pode inserir outro lote idêntico nas mesmas estruturas e dar continuidade ao processo produtivo. 


\section{REFERÊNCIAS}

ABRAMOVAY, R.; PIKETTY, M.G. Política de crédito do programa nacional de fortalecimento da agricultura familiar (pronaf): resultados e limites da experiência brasileira nos anos 90 . Cadernos de Ciência \& Tecnologia, Brasília, v. 22, n. 1, p. 53-66, 2005.

AVACI, A.B.; SOUZA, S.N.M.; CHAVES, L.I. et al. Avaliação econômico-financeira da microgeração de energia elétrica proveniente de biogás da suinocultura. Rev. Bras. Eng. Agríc. Ambient., v.17, p.456-462, 2013.

BERTECHINI, A.G. Situação atual e perspectivas para a coturnicultura no Brasil. In: SIMPÓSIO INTERNACIONAL, 4., / CONGRESSO BRASILEIRO DE COTURNICULTURA, 3., 2010. Lavras. Anais... Lavras: Universidade Federal de Lavras, 2010.

BRASIL. Ministério do Desenvolvimento Agrário. Agricultura familiar no Brasil e o censo agropecuário de 2006. Brasília, 2010. Disponível em:

$<$ HTTP://portal.mda.gov.br/portal/saf/arquivos/v iew/arquivos-destaque/censo_2006.pdf $>$.

Acessado em: 10 mar. 2015.

EUCLYDES, R.F.; TEIXEIRA, R.B.; SILVA, L.P. et al. Herdabilidade de características de produção e postura em matrizes de codornas de corte. Rev. Ciênc. Rural, v.43, p.361-365, 2013.

INSTITUTO BRASILEIRO DE GEOGRAFIA E ESTASTÍSTICA - IBGE. Produto Interno Bruto dos Municípios-2012. Disponível em: $<$ http://cidades.ibge.gov.br $>$ Acesso em: 01 set. 2015.

KATO, R.K. Importância do custo de produção na coturnicultura. In: SIMPÓSIO INTERNACIONAL DE COTURNICULTURA, 3., 2007, Lavras. Anais... Lavras: Universidade Federal de Lavras, 2007.
MATOS, E.H.S.F. Dossiê técnico: criação de codornas. Brasilia: CDT/UnB, 2007. 22p.

MATSUNAGA, M.; BEMELMAN, P.F.; TOLEDO, P.E.N. et al. Metodologia de custo utilizada pelo IEA. Agric. São Paulo, v.23, p.123-139, 1976.

MURAKAMI, A.E.; ARIKI, J. Produção de codornas japonesas. Jaboticabal: Funep, 1998. $79 \mathrm{p}$.

NASCIMENTO, A.M.; REGINATO, L. Controladoria: um enfoque na eficácia organizacional. 2.ed. São Paulo: Atlas, 2009.

NEVES, M.F. Introdução ao marketing, networks e agronegócios. São Paulo: Atlas, 2003. 358p.

PASTORE, S.M.; OLIVEIRA, W.P.; MUNIZ, J.C.L. Panorama da coturnicultura no Brasil. Rev. Elet. Nutrit., v.9, p.2041-2049, 2012.

PETROLLI, T.G.; MATEUS, K.; RODRIGUES, M. Criação de codornas: pequenas e lucrativas. SB Rural, 2p., 2011.

PRODUTO interno bruto dos municípios. [Rio de Janeiro]: IBGE, 2012. Disponível em: $<$ http://cidades.ibge.gov.br $>$ Acessado em: 01 set. 2015 .

REFORMA agrária: famílias assentadas. Distrito Federal: INCRA, 2015.

SABBAG, O.J.; NICODEMOS, D. Viabilidade econômica para produção de mel em propriedade familiar. Pesqui. Agropecu., v41, p.94-101, 2011.

SANGALLI, A.R.; SCHLINDWEIN, M.M. A contribuição da agricultura familiar para o desenvolvimento rural de Mato Grosso do Sul Brasil. Rev. Des. Reg., v.18, p.82-99, 2013.

SANTOS, J.L. O desenvolvimento local sustentável como ideologia do protagonismo social. Rev. Okara., v.6, p.60-68, 2012. 